\title{
Single-dose Intravenous Injection Toxicity of Water- soluble Danggui Pharmacopuncture (WDP) in Sprague-Dawley Rats
}

\author{
Sunju Park', Hae-Mo Park², Seung-Ho Sun ${ }^{3}$ \\ 1 Department of Preventive Medicine, College of Korean Medicine, Daejeon University, Daejeon, Korea. \\ ${ }^{2}$ Department of Preventive Medicine, College of Korean Medicine, Sangji University, Wonju, Gangwon, Korea. \\ ${ }^{3}$ Department of Internal Medicine, College of Korean Medicine, Sangji University, Wonju, Gangwon, Korea
}

\section{Key Words}

Acupuncture, aqua acupuncture, angelica gigantis radix, pharmacopuncture, single-dose toxicity test.

\begin{abstract}
Objective: This study is to evaluate both the single-dose intravenous injection toxicity and the approximate lethal dose of Water-soluble Danggui Pharmacopuncture (WDP) in Sprague-Dawley (SD) rats.

Methods: Toxicity experiments were conducted at Good Laboratory Practice (GLP) laboratory in Biotoxtech Co., according to the regulations of GLP. WDP injection of dose $0.125,0.25$, and $0.5 \mathrm{~mL} /$ animal were experimental groups and normal saline injection group was control group. WDP and normal saline were injected once to 6 - week old 5 male and 5 female SD rats at the tail veins at approximately $2 \mathrm{~mL} / \mathrm{min}$. During 14 days after the injection, general symptoms were observed and weight were measured. After the observation period, hematological and blood biochemical examination, macroscopic autopsy, topical resistance test at the injection area were performed.
\end{abstract}

Results: RThe WDP $0.5 \mathrm{~mL} /$ animal injection group in 4 cases of male rats and all cases of female rats showed

Received: Feb 28, 2018 Reviewed: Apr 24, 2018 Accepted: May 16, 2018

(c) This is an Open-Access article distributed under the terms of the Creative Common Attribution Non-Commercial License (http://creativecommons.org/licenses/by-nc/4.0/) which permits unrestricted noncommercial use, distribution, and reproduction in any medium, provided the original work is properly cited.

(@) This paper meets the requirements of KS X ISO 9706, ISO 9706-1994 and ANSI/NISO Z39.48-1992 (Permanence of Paper). hematuria 30 minutes after the administration. However, after 1 hour, no more abnormal general symptoms were observed. The WDP did not affect weight, hematological and blood biochemical examination, macroscopic autopsy, and topical resistance test at the injection area.

Conclusion: WDP single dose intravenous injection results showed that WDP have no toxic effects and a lethal dose of WDP should be over $0.5 \mathrm{~mL} / \mathrm{animal}$ in male and female rats under the study condition. So WDP may be safe.

\section{Introduction}

Pharmacopuncture is a new-typed acupuncture treatment to combine merits of acupuncture and herbal medicine and one of the most broadly used treatments in traditional Korean doctors (TKM) because of usefulness (1). The diverse types of pharmcopuncture have been developed such as eight principle pharmacopuncuture, meridian field pharmacopuncture, mountain ginseng pharmacopuncture (MGP), animal based pharmacopuncture, and pharmacopuncture for blood and qi recuperation and so on $(1,2)$.

Danggui (DG) belongs to a member of the Apiaceae family. The kinds of DG include Angelica gigas Nakai (AGN) in Korea, Angelica sinensis(Oliv.) Diels in China and Angelica acutiloba Kitag. in Japan. AGN is 
called Cham Dang Gui, namely Korean DG. The root of AGN, namely Angelica gigas radix (AGR), has been used to treat in Korea $(3,4)$. DG is called 'female ginseng' because DG has effect to tonify blood and has been used to treat many female diseases cause by blood deficiency $(5,6)$. In Dong-Ui-Bo-Gam, DG is major component medicinal herb among formulas used to treat female diseases related to menstruation, pregnancy and delivery, and postpartum disease (3). The effects of DG have reported to have anti-inflammation $(7,8)$, anti-platelet (9), anti-cancer (10), memory improvement (11), anti-bacteria (12), immune stimulation (13), anti-diabetics (14), and liver protection (15). DG contains fat-soluble ingredients, essential oil, and water-soluble ingredients (polysaccharide). Fat-soluble ingredients, such as decursin, decusinol angelate, umbelliferone and so on, account for large portion of DG ingredients and are one of main components that indicate a treatment effects (16).

Danggui pharmacopuncture (DGP) is the water-soluble pharmacopuncture, which makes fat-soluble ingredient and essential oil to dissolve in water. So active components of water-soluble DGP (WDP) can absorb the body easily and can represent good effects (4). The original pharmacopuncture is put on meridian points so they are either hypodermic or intramuscular injections. However, intravenously injecting pharmacopuncture increases the effectiveness of pharmacopuncture and will increase the application of diseases. Wild ginseng pharmacopuncture is being applied as intravenous injections as it preserves energy and various studies are being conducted on intravenous injections $(2,17-19)$.

The studies on intravenous injections of WDP have not been reported except for neuroprotective effect (20). Therefore, further research needs to be conducted. Intravenous injections can increase the effects of WDP but as it is processed right into the body without detoxification, safety is the most important aspect. Although there have reports assuring health safety in single toxicity tests for muscles (4), but there haven't been any safety reports regarding intravenous injections. Therefore, intravenous injection toxicity tests are necessary.

The aim of the study is to investigate toxicity reaction of WDP intravenous administration and lethal dose by using male and female Sprague-Dawley rats.

\section{Materials and Methods}

For WDP preparation, Korean angelica extraction was obtained by filtering grinded Korean angelica root $1 \mathrm{~kg}$ that was mixed at $80 \mathrm{rpm}$ with $70 \%$ ethanol $5 \mathrm{~L}$, during 6 hours at $60^{\circ} \mathrm{C}$. Then Angelica extraction $5 \mathrm{~kg}$ (extract + extract solvent) was condensed to $370 \mathrm{~g}$ Angelica concentration that included decursin and decursinol angelate. The Angelica extract and an emulsifier were quantified to the reaction beaker. To make water-soluble, WFI (Water for Injection-Fine FA, Korea) was added to the beaker and stir by high speed stirrer. Water solution was adjusted to $\mathrm{pH}$ 7.3 by $\mathrm{NaOH}$ solution. A filter ( $1 \mu \mathrm{m}$, satorius) equipment was set up between preparation tank and filling tank and emulsified solution was transferred to filling tank by N2 gas. After fractioning in the sterilized vial bottle, the bottle was kept refrigerated at $4^{\circ} \mathrm{C}$ after autoclaving 30 minutes at $121^{\circ} \mathrm{C}$ in the low temperature sterilizer (high pressure sterilizer, fine FA, KOREA).

In the study, Sprague-Dawley rats (ORIENTBIO INC., Korea) were used. When taking-in, visual inspection and weight measurement of the rats by electronic scale (CP3202S, Sartorius, Germany) were performed. during 7-day adaptation period, general symptoms were examined every day. To fetch animals, rats were transferred from quarantine to the animal room after observing general symptoms for 3 days. At the end of the adaptation day, weights were measured, and general symptoms were checked to confirm normality. At the time of IV injection, weight range of 6-week rats were 191.2 212.9 g males and $148.9 \sim 167.2 \mathrm{~g}$ females, 20 rats each. The raise condition were as follows: temperature $21.0 \sim 22.9^{\circ} \mathrm{C}$, ventilation frequency $10 \sim 15$ time/hour, relative humidity $43.2 \sim 59.6 \%$, lighting time 12 hour/day (7:00-19:00), and illumination intensity $150 \sim 300$ Lux. Rats were allowed to free intake of Telkad Certified Irradiated Global 18\% Protein Rodent Diet 2918C (Harlan Laboratories, INC., USA) solid feed from the feeding system.

The study was approved by the approval of the Institutional Animal Care and Use Committee according to Laboratory Animal Act in Biotoxtech Co. (Approval No: 130366). The study was followed by Good Laboratory Practice regulation (Ministry of Food and Drug Safety notification; MFDSn) and performed by Standard for Toxicity Study of Pharmaceuticals (MFDSn).

Groups were separated at the end of the adaptation day. At the group separation day, 20 males and 20 females rats that approximate mean weight, were selected. Selected animals were randomized into 4 groups to have equal mean weight, 5 rats per each group (Table 1). During observation period, individuals were marked at the tail of the rats with blue oil-based pen, and color individual identification cards were attached at the breeding cage.

As clinical application route will be intravenous, WDP was injected intravenously. Injection doses were $0.5 \mathrm{~mL} /$ animal for control and high-dose group, $0.125 \mathrm{~mL} /$ animal for low-dose group, and $0.25 \mathrm{~mL} /$ animal for middle-dose group (Table 1). The solutions were injected once at a speed of approximately $2 \mathrm{~mL} / \mathrm{min}$ at the tail vein with a disposable syringe ( $1 \mathrm{~mL}, 26 \mathrm{G})$. The scheduled WDP clinical dose is $1.0 \mathrm{~mL} /$ time.

The pilot test of the study (Biotoxtech Study No.: B13480P) that single dose IV injection to the male and female rats of $0.5 \mathrm{~mL} /$ animal, did not reported death case. Based on the pilot test results and discussion with the sponsor, the administration dose of the study was set to $0.5 \mathrm{~mL} /$ animal high-dose, and applied at the ratio of 2 for middle-dose and low-dose, 0.25 and $0.125 \mathrm{~mL} / \mathrm{animal}$, respectively. The same dose of high-dose group of normal saline was administrated to the control group.

At the injection day (day 0), general conditions (toxicity symptom types, onset time, recovery time, etc.) and death were observed 30 minutes, 1 hour, 2hour, 4 hour and 6 hour after the injection. General symptoms were observed daily during injection day 1 to day 14 . Weights were measured at injection day (before the injection), 3, 7 , and 14 days after the injection.

All animals were fasted more than 18 hours before the au- 
topsy for hematological test. At the autopsy day (15 days after the administration), animals were anesthetized with isoflurane and blood was gathered from the abdominal aorta. Blood $1 \mathrm{~mL}$ was collected in the EDTA tube to analyze by the blood corpuscle analyzer (ADVIA 120, SIEMENS, Germany). Erythrocyte count (RBC), hematocrit (HCT), hemoglobin (HGB), mean corpuscular hemoglobin $(\mathrm{MCH})$, mean corpuscular hemoglobin concentration (MCHC), mean corpuscular volume (MCV), platelet (PLT), leucocyte count (WBC), neutrophils (NEU), eosinophils (EOS), basophils (BASO), reticulocytes (Reti), lymphocytes (LYM), monocytes (MONO) were measured. For blood coagulation test, blood plasma was taken by following methods: collected blood $2 \mathrm{~mL}$ were kept in the $3.2 \%$ sodium citrate tube, followed by 3,000 rpm centrifuge for 10 minutes. Prothrombin time (PT) and activated partial thromboplastin time (aPTT) were checked by the coagulation time analyzer (Coapresta 2000, SEKISUI, Japan).

For blood biochemical examination, the remained blood collected from the abdominal aorta was centrifuged by $3,000 \mathrm{rpm}$ for 10 minutes to get blood serum. Blood biochemical analyzer (7180, HITACHI, Japan) were applied to analyze alanine aminotransferase (ALT), aspartate aminotransferase (AST), alkaline phosphatase (ALP), g amma glutamyl transpeptidase ( $\bigotimes$-GTP), total bilirubin (T-Bili), total protein (TP), albumin (Alb), A/G ratio, total cholesterol (T-Chol), triglycerides (TG), blood urea nitrogen (BUN), creatinine (Cr), glucose (Glu), and calcium (Ca), phosphorus (P) were measured. In addition, electrolyte analyzer (AVL9181, Roche, Germany) was used to measure chloride $(\mathrm{Cl})$, sodium $(\mathrm{Na})$, and potassium $(\mathrm{K})$.

For autopsy, detail macroscopic inspection was conducted for organs and tissues of the entire bodies of all animals. All organs and tissues were removed and fixed in the $10 \%$ neutral buffered formalin from the autopsied animals for histopathological examination. Fixed organs and tissues were turned, dehydrated, and praffin embedded to make tissue sections. The tissue sections were cut into thin slic- es and stained with hematoxylin \& eosin (H\&E). The grey matters of the bone tissues were removed by Calci-ClearRapidTM solution (National diagnostics, U.S.A.). The remained organs and tissues were kept in the $10 \%$ neutral buffered formalin. A local tolerance test was done at the injection site of all animals.

For statistical analyses, weight, hematological and blood biochemical examination results were tested by SAS (version 9.3, SAS Institute Inc., U.S.A.). Bartlett test was used for equal variance assumption (significance level at 0.05). When equal variance assumption was satisfied, one-way analysis of variance (ANOVA) was applied at the significance level 0.05. For post-hoc analysis, Dunnett's t-test was used (significance level at 0.05 or 0.01 ). When equal variance assumption was not satisfied, Kruskal-Wallis test was used (significance level 0.05) for testing the differences between groups.

\section{Results}

There were no death cases in both gender control and WDP injection groups during the observation period (Table 2). No abnormal general symptoms were observed in male and female control and WDP 0.125, and $0.25 \mathrm{~mL} / \mathrm{animal}$ injection groups. Hematuria were detected in WDP 0.5 $\mathrm{mL} /$ animal injection group 30 minutes after the injection in 4 male rats and all of the female rats. However, from 1 hour after the injection, no abnormal symptoms were observed (Table 3,4 ).

During the observation period, there were no statistical significant differences in weight changes between WDP and control groups (Figure 1, 2).

No meaningful changes in hematological parameters, such as RBC, HCT, MCH, MCHC, MCV, WBC, NEU, EOS, BASO, Reti, LYM, MONO, PT, and aPTT, were detected in both male and female WDP injection groups. Otherwise, changes in both HGB and PLT in male rates were non dose-dependent minor changes that did not have toxicity. No significant changes in blood biochemical parameters,

Table 1 Grouping of the animals

\begin{tabular}{lccc}
\hline Group & $\begin{array}{c}\text { Injection dose } \\
\text { (mL/animal) }\end{array}$ & male & female \\
\hline G1: Control group & 0.5 (saline) & 5 & 5 \\
G2: Low-dose group & 0.125 (WDP) & 5 & 5 \\
G3: Mid-dose group & 0.25 (WDP) & 5 & 5 \\
G4: High-dose group & 0.5 (WDP) & 5 & 5 \\
\hline
\end{tabular}

WDP: Water-soluble Danggui pharmacopuncture 
Table 2 Summary of Mortality

\begin{tabular}{|c|c|c|c|c|c|c|c|c|c|c|c|c|c|c|c|c|c|c|}
\hline \multirow{2}{*}{ Sex } & \multirow{2}{*}{$\begin{array}{l}\text { Group / } \\
\text { Dose } \\
\text { (mL/animal) }\end{array}$} & \multirow{2}{*}{$\begin{array}{c}\text { No. of } \\
\text { animals }\end{array}$} & \multicolumn{15}{|c|}{ Days after dosing } & \multirow{2}{*}{ Mortality } \\
\hline & & & 0 & 1 & 2 & 3 & 4 & 5 & 6 & 7 & 8 & 9 & 10 & 11 & 12 & 13 & 14 & \\
\hline \multirow[t]{8}{*}{ Male } & G1 (saline) & 5 & 0 & 0 & 0 & 0 & 0 & 0 & 0 & 0 & 0 & 0 & 0 & 0 & 0 & 0 & 0 & $\begin{array}{c}0 / 5 \\
(0 / 5)\end{array}$ \\
\hline & 0 & & & & & & & & & & & & & & & & & \\
\hline & G2 (WDP) & 5 & 0 & 0 & 0 & 0 & 0 & 0 & 0 & 0 & 0 & 0 & 0 & 0 & 0 & 0 & 0 & $\begin{array}{c}0 / 5 \\
(0 / 5)\end{array}$ \\
\hline & 0.125 & & & & & & & & & & & & & & & & & \\
\hline & G3 (WDP) & 5 & 0 & 0 & 0 & 0 & 0 & 0 & 0 & 0 & 0 & 0 & 0 & 0 & 0 & 0 & 0 & $\begin{array}{c}0 / 5 \\
(0 / 5)\end{array}$ \\
\hline & 0.25 & & & & & & & & & & & & & & & & & \\
\hline & G4 (WDP) & 5 & 0 & 0 & 0 & 0 & 0 & 0 & 0 & 0 & 0 & 0 & 0 & 0 & 0 & 0 & 0 & $\begin{array}{c}0 / 5 \\
(0 / 5)\end{array}$ \\
\hline & 0.5 & & & & & & & & & & & & & & & & & \\
\hline \multirow[t]{8}{*}{ Female } & G1 (saline) & 5 & 0 & 0 & 0 & 0 & 0 & 0 & 0 & 0 & 0 & 0 & 0 & 0 & 0 & 0 & 0 & $\begin{array}{c}0 / 5 \\
(0 / 5)\end{array}$ \\
\hline & 0 & & & & & & & & & & & & & & & & & \\
\hline & G2(WDP) & 5 & 0 & 0 & 0 & 0 & 0 & 0 & 0 & 0 & 0 & 0 & 0 & 0 & 0 & 0 & 0 & $\begin{array}{c}0 / 5 \\
(0 / 5)\end{array}$ \\
\hline & 0.125 & & & & & & & & & & & & & & & & & \\
\hline & G3(WDP) & 5 & 0 & 0 & 0 & 0 & 0 & 0 & 0 & 0 & 0 & 0 & 0 & 0 & 0 & 0 & 0 & $\begin{array}{c}0 / 5 \\
(0 / 5)\end{array}$ \\
\hline & 0.25 & & & & & & & & & & & & & & & & & \\
\hline & G4(WDP) & 5 & 0 & 0 & 0 & 0 & 0 & 0 & 0 & 0 & 0 & 0 & 0 & 0 & 0 & 0 & 0 & $\begin{array}{c}0 / 5 \\
(0 / 5)\end{array}$ \\
\hline & 0.5 & & & & & & & & & & & & & & & & & \\
\hline
\end{tabular}

WDP: Water-soluble Danggui pharmacopuncture

Table 3 Summary of Clinical Signs by hours after dosing

\begin{tabular}{|c|c|c|c|c|c|c|c|c|}
\hline \multirow{2}{*}{ Sex } & \multirow{2}{*}{$\begin{array}{l}\text { Group / } \\
\text { Dose } \\
\text { (mL/animal) }\end{array}$} & \multirow{2}{*}{$\begin{array}{l}\text { No. of } \\
\text { animals }\end{array}$} & \multirow{2}{*}{ Clinical sign } & \multicolumn{5}{|c|}{ Hours (Day 0) after dosing } \\
\hline & & & & 0.5 & 1 & 2 & 4 & 6 \\
\hline \multirow[t]{4}{*}{ Male } & $\begin{array}{l}\text { G1 (saline) } \\
0\end{array}$ & 5 & NOA & 5 & 5 & 5 & 5 & 5 \\
\hline & $\begin{array}{l}\text { G2 (WDP) } \\
0.125\end{array}$ & 5 & NOA & 5 & 5 & 5 & 5 & 5 \\
\hline & $\begin{array}{l}\text { G3 (WDP) } \\
0.25\end{array}$ & 5 & NOA & 5 & 5 & 5 & 5 & 5 \\
\hline & $\begin{array}{l}\text { G4 (WDP) } \\
0.5\end{array}$ & 5 & $\begin{array}{l}\text { NOA } \\
\text { Hematuria }\end{array}$ & $\begin{array}{l}1 \\
4\end{array}$ & 5 & 5 & 5 & 5 \\
\hline \multirow[t]{4}{*}{ Female } & $\begin{array}{l}\text { G1 (saline) } \\
0\end{array}$ & 5 & NOA & 5 & 5 & 5 & 5 & 5 \\
\hline & $\begin{array}{l}\text { G2 (WDP) } \\
0.125\end{array}$ & 5 & NOA & 5 & 5 & 5 & 5 & 5 \\
\hline & $\begin{array}{l}\text { G3 (WDP) } \\
0.25\end{array}$ & 5 & NOA & 5 & 5 & 5 & 5 & 5 \\
\hline & $\begin{array}{l}\text { G4 (WDP) } \\
0.5\end{array}$ & 5 & $\begin{array}{l}\text { NOA } \\
\text { Hematuria }\end{array}$ & 5 & 5 & 5 & 5 & 5 \\
\hline
\end{tabular}

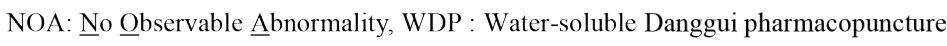


Table 4 Summary of Clinical Signs by hours after dosing

\begin{tabular}{|c|c|c|c|c|c|c|c|c|c|c|c|c|c|c|c|c|c|}
\hline \multirow{2}{*}{ Sex } & \multirow{2}{*}{$\begin{array}{l}\text { Group / } \\
\text { Dose } \\
\text { (mL/animal) }\end{array}$} & \multirow{2}{*}{$\begin{array}{l}\text { No. of } \\
\text { animals }\end{array}$} & \multirow{2}{*}{ Clinical sign } & \multicolumn{14}{|c|}{ Days after dosing } \\
\hline & & & & 1 & 2 & 3 & 4 & 5 & 6 & 7 & 8 & 9 & 10 & 11 & 12 & 13 & 14 \\
\hline \multirow[t]{4}{*}{ Male } & $\begin{array}{l}\text { Gl (saline) } \\
0\end{array}$ & 5 & NOA & 5 & 5 & 5 & 5 & 5 & 5 & 5 & 5 & 5 & 5 & 5 & 5 & 5 & 5 \\
\hline & $\begin{array}{l}\text { G2 (WDP) } \\
0.125\end{array}$ & 5 & NOA & 5 & 5 & 5 & 5 & 5 & 5 & 5 & 5 & 5 & 5 & 5 & 5 & 5 & 5 \\
\hline & $\begin{array}{l}\text { G3 (WDP) } \\
0.25\end{array}$ & 5 & $\mathrm{NOA}$ & 5 & 5 & 5 & 5 & 5 & 5 & 5 & 5 & 5 & 5 & 5 & 5 & 5 & 5 \\
\hline & $\begin{array}{l}\text { G4 (WDP) } \\
0.5\end{array}$ & 5 & NOA & 5 & 5 & 5 & 5 & 5 & 5 & 5 & 5 & 5 & 5 & 5 & 5 & 5 & 5 \\
\hline \multirow[t]{4}{*}{ Female } & $\begin{array}{l}\text { Gl (saline) } \\
0\end{array}$ & 5 & NOA & 5 & 5 & 5 & 5 & 5 & 5 & 5 & 5 & 5 & 5 & 5 & 5 & 5 & 5 \\
\hline & $\begin{array}{l}\text { G2 (WDP) } \\
0.125\end{array}$ & 5 & $\mathrm{NOA}$ & 5 & 5 & 5 & 5 & 5 & 5 & 5 & 5 & 5 & 5 & 5 & 5 & 5 & 5 \\
\hline & $\begin{array}{l}\text { G3 (WDP) } \\
0.25\end{array}$ & 5 & NOA & 5 & 5 & 5 & 5 & 5 & 5 & 5 & 5 & 5 & 5 & 5 & 5 & 5 & 5 \\
\hline & $\begin{array}{l}\text { G4 (WDP) } \\
0.5\end{array}$ & 5 & NOA & 5 & 5 & 5 & 5 & 5 & 5 & 5 & 5 & 5 & 5 & 5 & 5 & 5 & 5 \\
\hline
\end{tabular}

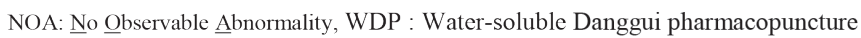

Table 5 Summary of Clinical Signs by hours after dosing

\begin{tabular}{lcccc|cccc} 
Sex & \multicolumn{5}{c}{ Male } & \multicolumn{4}{c}{ Female } \\
\hline Group & G1 & G2 & G3 & G4 & G1 & G2 & G3 & G4 \\
Dose (mL/animal) & 0 & 0.125 & 0.25 & 0.5 & 0 & 0.125 & 0.25 & 0.5 \\
No. of animals & 5 & 5 & 5 & 5 & 5 & 5 & 5 & 5 \\
\hline Unremarkable findings & 5 & 5 & 5 & 5 & 5 & 5 & 5 & 5 \\
no, of examined & 5 & 5 & 5 & 5 & 5 & 5 & 5 & 5 \\
\hline
\end{tabular}

External surface and all organs in body cavity were remarkable.

Table 6 Summary of Histopathological Findings

\begin{tabular}{|c|c|c|c|c|c|c|}
\hline \multirow{4}{*}{$\begin{array}{l}\text { Organ / } \\
\text { Findings }\end{array}$} & \multirow{2}{*}{$\begin{array}{l}\text { Sex } \\
\text { Group / }\end{array}$} & & \multicolumn{4}{|c|}{ Male } \\
\hline & & & Gl & G2 & G3 & G4 \\
\hline & Dose (mL/animal) & & 0 & 0.125 & 0.25 & 0.5 \\
\hline & No. of animals & & 5 & 5 & 5 & 5 \\
\hline \multirow[t]{3}{*}{ Injection site } & Remarkable findings & & 0 & 0 & 0 & 0 \\
\hline & & No. of examined & 5 & 5 & 5 & 5 \\
\hline & Sex & & \multicolumn{4}{|c|}{ Female } \\
\hline \multirow{3}{*}{$\begin{array}{l}\text { Organ / } \\
\text { Findings }\end{array}$} & Group / & & G1 & G2 & G3 & G4 \\
\hline & Dose (mL/animal) & & 0 & 0.125 & 0.25 & 0.5 \\
\hline & No. of animals & & 5 & 5 & 5 & 5 \\
\hline \multirow[t]{3}{*}{ Injection site } & $\begin{array}{l}\text { - Cell infiltration, inflammatory, } \\
\text { focal }\end{array}$ & \pm & 0 & 1 & 0 & 0 \\
\hline & - Crust, epidermis & \pm & 0 & 0 & 0 & 1 \\
\hline & & No. of examined & 5 & 5 & 5 & 5 \\
\hline
\end{tabular}


such as ALT, AST, ALP, 囚-GTP, T-Bili, TP, Alb, A/G ratio, T-Chol, TG, BUN, Cr, Glu, Ca, P, Cl, Na, and $\mathrm{K}$, were observed in male and female WDP administration groups. Mild other changes were observed sporadically without dose-dependency. No macroscopic abnormal findings were detected in male and female WDP groups at macroscopic autopsy (Table 5). Topical resistance test at the injection area of both gender rats showed that there were no effects by the test materials. Other histopathological examination results showed that they were natural occurrence or accidental changes that were irrelevant with toxicity (Table 6).

\section{Discussion}

DG contains decursin, $\bigotimes$-pinene, limonene, decurisinol nodakenen, $\bigotimes$-sistosterol, stigmasterol and so on (3) and includes both water-soluble ingredients and essential oil (4). DG enhance axonal regrowth by the induction of GAP-43 expression and retrograde transport of phospho-Erk1/2 protein from the injury site to the cell body after sciatic nerve injury (21). AGR can suppress the reactive gliosis which disturbs the astrocyte regeneration in the brain of the rat with cerebral infarction after MCAO by controlling the expression of CD81 and GFAP. The effect may be modulated by the up-regulation of c-Fos and
ERK (20). AGR ethanol extract attenuate inflammation through inhibition of NO production and iNOS expression by blockade of NK- $\triangle \mathrm{B}$ activation in LPS-stimulated RAW 264. Cells (22). AGR prevent formation of cystic follicles and malfunction of ovary in polycystic ovary rat (23). AGR evaluates the collagenase and tyrosinase activity and reduce the metalloproteinase-1(MMP-1) activity (anti-MMP-1) (24). So DG has a wide range of therapeutic applications because DG can have potential as anti-aging, nerve-protecting, and anti-polycystic ovary ingredient in addition to have the effect to tonify and activate of blood and the effect of anti-inflammation and anti-platelet. DGP also has a wide range of application. DGP research only reports on the anti- inflammatory effect (25), so further various research is needed. DGP, which contains essential oils, is a possibility to be turn sour without being absorbed under the skin. Therefore, WDP has been developed to maximize the effects of essential oils and water-soluble ingredients, and the essential oil component has been developed to facilitate absorption in the body (4). Pharmacopuncture is divided into an intramuscular injection into the acupuncture point and a vascular injection into the vein according to the insertion method. In general, the method of intramuscular injection takes up a large part (1). However, vascular injections are used to achieve difficult or rapid effects of oral administration of herbal medi-
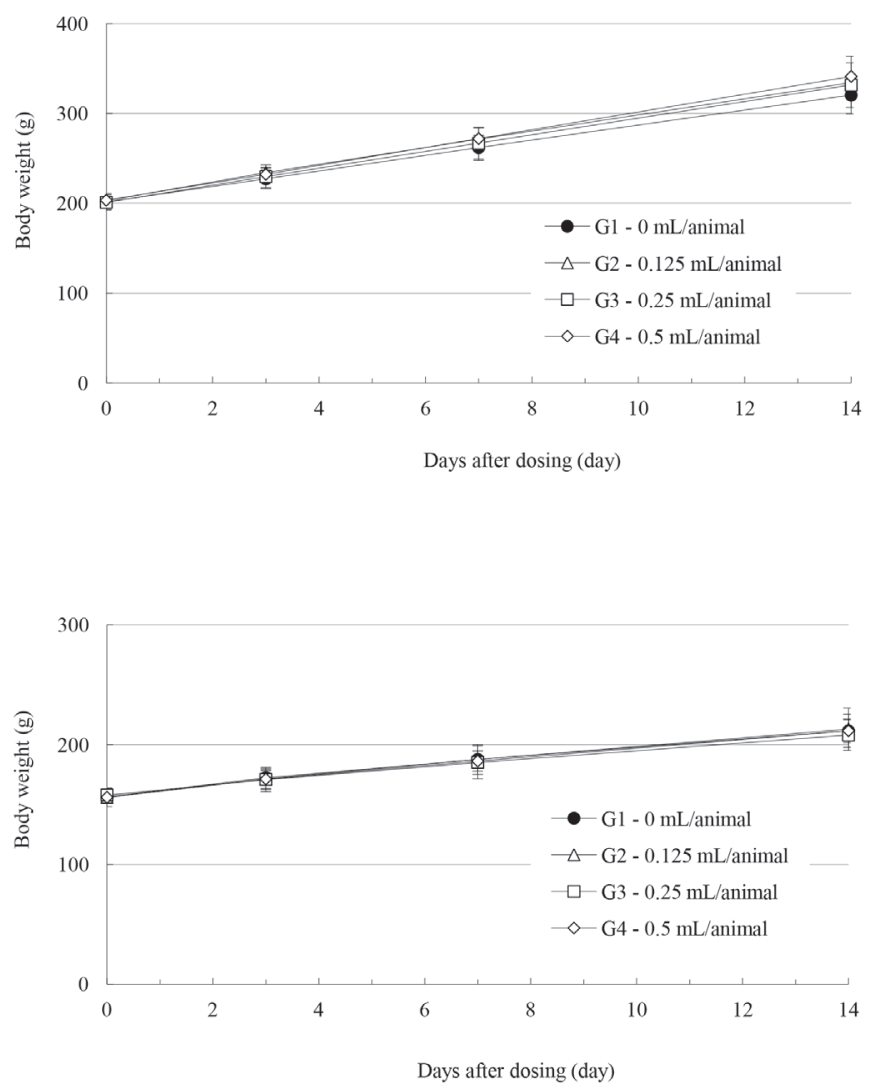

Figure 1

Body Weights in Male SD Rats
Figure 2

Body Weights in Female SD Rats $\backslash$ 
cines. MGP among vascular injection pharmacopunctures, that is intravenous injection pharmacopuncture (IIP), are representative, and it is mainly used for anti-cancer therapy in clinical practice (26). In China, since 1940, IIP has been developed and applied in various ways. In Korea, in addition to MGP, we have been working on the development of IIP such as daebohwalryeok pharmcopuncture (2), watersoluble ginseng pharmacopuncture (19), Gamisoyo-san pharmcopuncture (27), Water-soluble Carthami-flos pharmacopuncture (28), and Saeng Maek San pharmacopuncture (29). WDP is also highly likely to be developed as IIP. However, IIP requires efficacy, but its safety is very important. We performed single-dose toxicity test to evaluate safety of WDP intravenous administration at first. The results of toxicity test showed that hematuria was detected in WDP $0.5 \mathrm{~mL} /$ animal injection group 30 minutes after the injection in 4 male rats and all of the female rats, but not was observed from 1 hour after the injection. Slight changes of male and female WDP administration groups in blood biochemical examination were not considered to be toxic because of sporadic observations without dose-dependency. This single-dose toxicity test has shown that WDP does not have toxic effects. Further a long-tern toxicity test, such as a 4-week, repeated-dose, toxicity test, and pharmacological test should be conducted.

\section{Conclusion}

WDP single dose intravenous injection results showed that WDP have no toxic effects and a lethal dose of WDP should be over $0.5 \mathrm{~mL} /$ animal in male and female rats under the study condition. So WDP may be safe.

\section{Acknowledgments}

This research was supported by Sangji University Research Fund, 2016.

\section{Conflict of interest}

The authors declare that there are no the conflict of interest. 


\section{References}

1. Lee KH, Cho YY, Kim S, Sun SH. History of Research on Pharmacopuncture in Korea. J Pharmacopuncture. 2016; 19(2):101-8.

2. Sun SH, Park S, Jeong JJ, Lee KH, Yu JS, Seo HS, et al. Single-dose Intravenous Toxicology Testing of Daebohwalryeok Pharmcopuncture in Sprague-Dawley Rats. J Pharmacopuncture. 2015; 18(2):42-50.

3. Lee HI, Yoo DY. The study on the use of Angelicae Gigantis Radix in uterus and gynecology part of Dongeuibogam. J Korean Obstet Gnecol. 2015; 28(3):40-53.

4. Sun SH, Jeong JJ, Park S, Lee KH, Yu JS, Seo HS, et al. Single-dose Intramuscular Injection Toxicology of Danggui Pharmacopuncture (DGP) in Sprague-Dawley Rats. J Pharmacopuncture. 2015; 18(1):56-62.

5. Park YC, Lee JS, Kim MH, Kim DY, Lee Sd. Pharmacological action and toxicity of Angelica sinensis. The Korean Journal of Oriental Medical Prescription 2011; 19(2):93-108. Korean.

6. National oriental medicine school codeitoship of herbal medicines professors. Medicine of tonifying blood. Herbal medicine. 2nd edition ed. Seoul: Youngrimsa; 2008. p. 127, 629-31. Korean.

7. Cho JH, Kwon JE, Cho Y, Kim I, Kang SC. Anti-Inflammatory Effect of Angelica gigas via Heme Oxygenase (HO)-1 Expression. Nutrients. 2015; 7(6):4862-74.

8. Han HS. Anti-inflammatory effect of Angelicae acutilobae Radix water extract on LPS-stimlated mous macrophages. Kor J Herbology. 2013; 28(6):129-33. Korean.

9. Lee YY, Lee S, Jin JL, Yun-Choi HS. Platelet anti-aggregatory effects of coumarins from the roots of Angelica genuflexa and A. gigas. Arch Pharm Res. 2003; 26(9):723-6.

10. Zhang J, Li L, Jiang C, Xing C, Kim SH, Lu J. Anti-cancer and other bioactivities of Korean Angelica gigas Nakai (AGN) and its major pyranocoumarin compounds. Anticancer Agents Med Chem. 2012; 12(10):1239-54.

11. Kang SY, Lee KY, Park MJ, Kim YC, Markelonis GJ, Oh $\mathrm{TH}$, et al. Decursin from Angelica gigas mitigates amnesia induced by scopolamine in mice. Neurobiol Learn Mem. 2003; 79(1):11-8.

12. Lee S, Shin DS, Kim JS, Oh KB, Kang SS. Antibacterial coumarins from Angelica gigas roots. Arch Pharm Res. 2003; 26(6):449-52.

13. Han SB, Kim YH, Lee CW, Park SM, Lee HY, Ahn KS, et al. Characteristic immunostimulation by angelan isolated from Angelica gigas Nakai. Immunopharmacology. 1998; 40(1):39-48.

14. Kim HM, Kang JS, Park SK, Lee K, Kim JY, Kim YJ, et al. Antidiabetic activity of angelan isolated from Angelica gigas Nakai. Arch Pharm Res. 2008; 31(11):1489-96.

15. Son HS, Kim YC. Inhibitory effect of Angelica Gigantis Radix on fibrogenesis in rat hepatic stellate cells. Korean J Orient Int Med. 2010; 31(3):415-24.

16. Kim SA, Oh HK, Kim JY, Hong JW, Cho SI. A review of pharmacological effects of Angelica gigas, Angelica sinensis, Angelica acutiloba and their bioactive compounds. J Korean Oriental Med. 2011; 32(4):1-24. Korean.

17. Kwon KR, Yu JS, Sun SH, Lee KH. Study of Intravenous
Single-Dose Toxicity Test of Bufonis venonum Pharmacopuncture in Sprague-Dawley Rats. J Pharmacopuncture. 2016; 19(2):155-62.

18. Lee K, Yu J, Sun S, Kwon K, Lim C. A 4-week, repeated, intravenous dose, toxicity test of mountain ginseng pharmacopuncture in sprague-dawley rats. J Pharmacopuncture. 2014; 17(4):27-35.

19. Yu JS, Sun SH, Lee KH, Kwon KR. Intravenous Toxicity Study of Water-soluble Ginseng Pharmacopuncture in SD Rats. J Pharmacopuncture. 2015; 18(4):38-44.

20. Song BK, Jeon YC, Kim SA, Shim AN, Seong KM, Lee EJ. The effect of intravenous injection of the water extract of Angelica gigas Nakai on gliosis in the middle cerebral artery occlusion rats. J Pharmacopuncture. 2011; 14(3):5-17.

21. Hong SS, Oh MS. Improved axonal regeneration responses in the injured sciatic nerve of rats by Danggui treatment. J Korean Oriental Med. 2008; 29(2):133-50. Korean.

22. Jeong My, Park HJ, Jeong JH, Kim JY, Kang JM, Lee NK, et al. Inhibitory effect of Angelica gigas Nakai extract on nitric oxide production in RAW 264.7 cells. J Korean Oriental Med. 2007; 28(2):155-65.

23. Kim HW, Choi EG, Chung HJ, Joung YM, Shin SD, Cho SI. Effects of Angelicae Gigantis Radix (AGR) on polycystic ovary induced by estradiol valerate in rats. Kor J Herbology. 2011; 26(1):81-5. Korean.

24. Lee JH, Lee S, Kim MG, Kim MH, Kim HJ, Jo HJ, et al. Effects of Angelica Gigantis Radix extracts on the collagenase activity and procollagen synthesis in HS68 human fibroblasts and tyrosinase activity. Kor J Herbology. 2011; 26(1):29-33. Korean.

25. Ryu MS, Yun YC, Kim JH. The effect of Angelica gigas NAKAI pharmacopuncture at ST36 and BL23 on Freund's adjuvant arthritis in rats. The Journal of Korean Acupuncture \& Moxibustion Society. 2010; 27(5):25- 34. Korean.

26. Park S, Joo J. Analysis of Case Report Related with Mountain Ginseng Pharmacopuncture in Korean Medical Database. J of Kor Traditional Oncology. 2015; 20(2):51-9. Korean.

27. Lee C, Yun J, Yim Y. The Effect of Gamisoyo-san Intravenous Pharmacopuncture on Restoration of Liver Function after Partial Hepatectomy in SD Rat. J Korean Med. 2015; 36(1):22-32.

28. Jung D, Choi Y, Kim S, Kim J, Yook T. Single Intravenous-dose Toxicity of Water-soluble Carthami-flos Pharmacopuncture (WCF) in Rats. J Pharmacopuncture. $2014 ; 17(3): 31-9$.

29. Choi M, Kim S, Cho S. Intravenous Injection of Saeng Maek San - A Safe Method of Treatment in Rats. J Pharmacopuncture. 2014; 17(2):67-72. 